\title{
Considerations in healthcare reform for patients and families with genetic diseases: a statement of the American College of Medical Genetics and Genomics
}

\author{
ACMG Board of Directors ${ }^{1}$
}

Disclaimer: These recommendations are designed primarily as an educational resource for medical geneticists and other health-care providers, to help them provide quality medical genetic services. Adherence to these recommendations does not necessarily assure a successful medical outcome. These recommendations should not be considered inclusive of all proper procedures and tests or exclusive of other procedures and tests that are reasonably directed to obtaining the same results. In determining the propriety of any specific procedure or test, the geneticist should apply his or her own professional judgment to the specific clinical circumstances presented by the individual patient or specimen. It may be prudent, however, to document in the patient's record the rationale for any significant deviation from these recommendations.

Genet Med advance online publication 1 February 2018

Key Words: ACMG statement; genetic diseases; health-care reform

\section{DISCLOSURE}

The American College of Medical Genetics and Genomics advocates for all patients with heritable conditions, including genetic diseases such as cystic fibrosis, sickle cell disease, TaySachs disease, inherited cancers, and cardiovascular disease. Given the centrality of genetics to human health, the College supports health-care reforms that
- Decrease barriers to diagnosis

- Provide coverage for individuals with pre-existing conditions

- Enable early disease detection and prevention

- Ensure access to affordable treatments, including specialty drugs, medical foods, and other emerging therapeutics The authors declare no conflict of interest.

\footnotetext{
${ }^{1}$ American College of Medical Genetics and Genomics, Bethesda, Maryland, USA. Correspondence: Michael S. Watson (mwatson@acmg.net)

The Board of Directors of the American College of Medical Genetics and Genomics approved this statement on 27 November 2017. 